\title{
Maternal and Neonatal Death Review (MNDR): A Useful Approach to Identifying Appropriate and Effective Maternal and Neonatal Health Initiatives in Bangladesh
}

\author{
Animesh Biswass,2*, Fazlur Rahman², Abdul Halim²,3, Charli Eriksson', Koustuv Dalal1 \\ ${ }^{1}$ Department of Public Health Science, School of Health and Medical Sciences, Örebro University, Örebro, \\ Sweden \\ ${ }^{2}$ Centre for Injury Prevention and Research (CIPRB), Dhaka, Bangladesh \\ ${ }^{3}$ Department of Obstetrics and Gynaecology, Kumudini Women's Medical College, Tangail, Bangladesh \\ Email: ${ }^{*}$ animesh.biswas@oru.se, ${ }^{*}$ animesh@ciprb.org
}

Received 3 May 2014; revised 18 June 2014; accepted 1 July 2014

Copyright (C) 2014 by authors and Scientific Research Publishing Inc.

This work is licensed under the Creative Commons Attribution International License (CC BY). http://creativecommons.org/licenses/by/4.0/

(c) (i) Open Access

\begin{abstract}
Objectives: To identify the effects of Maternal and Neonatal Death Review (MNDR) in terms of improving maternal and neonatal health at the community level in Bangladesh. Methods: Both quantitative and qualitative methods were undertaken for collecting data in Kashipur Union, Bangladesh. Death notifications from households, subsequent data collections from a focus-group discussion (FGD), a group discussion (GD) and in-depth interviews (IDIs) were obtained using structured tools and guidelines. Results: A total of four maternal deaths, 21 neonatal deaths and 15 still births were reported in the MNDR death notification system at Kashipur Union in 2010. Data were presented to local programme managers, who took various initiatives including awareness programmes, pregnancy registration, antenatal care, birth planning, and also the revitalization of a community clinic. The coverage of antenatal care, delivery in clinics, postnatal care and referral of complications increased through the active participation of the community. Community healthcare providers, care recipients and members of the community expressed satisfaction with the quality of maternal and neonatal services. In the preceding two years, maternal and neonatal deaths substantially reduced in Kashipur (in 2011 maternal death $=1$, neonatal death $=20$, still birth = 8; in 2012 maternal death = 1, neonatal death = 8, still birth = 13). Conclusions: The MNDR system successfully delivered notification of all maternal and neonatal deaths in the defined area and collected information for the formulation and implementation of specific interventions, which resulted in visible and tangible changes in care-seeking and client satisfaction.
\end{abstract}

\footnotetext{
${ }^{*}$ Corresponding author.
}

How to cite this paper: Biswas, A., Rahman, F., Halim, A., Eriksson, C. and Dalal, K. (2014) Maternal and Neonatal Death Review (MNDR): A Useful Approach to Identifying Appropriate and Effective Maternal and Neonatal Health Initiatives in Bangladesh. Health, 6, 1669-1679. http://dx.doi.org/10.4236/health.2014.614198 


\section{Keywords}

\section{Maternal and Neonatal Health, Death Review, Primary Healthcare, Bangladesh}

\section{Introduction}

Bangladesh has made remarkable progress in achieving Millennium Development Goals (MDGs) 4 and 5. Since 1990, there has been an effective reduction in maternal and child mortality [1]. The country has experienced a significant decline in infant and under-5 mortality, and also in maternal mortality over the past decade [2] [3]. At the same time, maternal mortality continues to be a major cause of death among women of reproductive age in many countries [4]. In developing countries, most maternal, perinatal and late neonatal deaths and morbidities occur at home, and multi-factorial interventions are needed to meet the challenges involved. However, the majority of the maternal and neonatal deaths occurring in developing countries are mostly avoidable [5]-[7]. Maternal and Perinatal Death Review (MPDR) is an evidence-based approach to intervention that involves the systematic evaluation of the medical and social factors concerned with maternal and perinatal deaths, which is then followed by the taking of appropriate actions to reduce them [8] [9]. Maternal Death Review (MDR) has been identified as a key element in the strategy to improve the quality of maternal healthcare services. MDR focuses on the causation of deaths and what could have been done to avert each one of them [1]. Striving for the highest quality of reporting, in terms of universal coverage and reliability, it is essential for informing actions to prevent maternal deaths, and for supporting the human right to be acknowledged in both life and death [10]. In maternal and perinatal death review (MPDR), death notification is a key component in preventing maternal and perinatal deaths in both developing and developed countries. The right kind of information, particularly on medical and social causes of deaths, is essential for designing appropriate programme interventions so that these deaths can be averted [5]-[7] [11]. Maternal and neonatal death review (MNDR) is practised in developed countries and in the South East Asian region, while maternal and perinatal death review (MPDR) is performed in India, Nepal, Pakistan, Sri Lanka, and the Maldives [12]-[14]. Bangladesh, however, did not have a maternal and neonatal death review system for identifying the causes of deaths of mothers and the newborn. Having a death review system is crucial to achieving the Millennium Development Goals by 2015, since it addresses causes of maternal and neonatal deaths and discovers ways of preventing them.

The Directorate General of Health Services (DGHS) of Bangladesh, in collaboration with the Directorate General of Family Planning (DGFP) of the Ministry of Health and Family Welfare (MOHFW) of Government of the People's Republic of Bangladesh, and with technical assistance from UNICEF Bangladesh and the Centre for Injury Prevention and Research, Bangladesh (CIPRB), initiated MNDR through the national health system to notify maternal, neonatal deaths and still births in the Thakurgaon District of Bangladesh in 2010. Subsequently, verbal and social autopsies were conducted by trained government healthcare providers. The findings were used by the health system to improve the quality of services, and to take action to reduce maternal and neonatal mortality and morbidity. Policy-makers at national level and programme managers in the directorates took the steps necessary for further measures to be taken.

This study aimed to explore the usefulness of maternal and neonatal death review (MNDR) in identifying appropriate and effective initiatives for maternal and neonatal health interventions in a district of Bangladesh.

\section{Methods}

The MNDR mechanism was developed though a number of technical group meetings, workshops, and consensus meetings at national and district level, with technical expertise from government, non-government partners, and national stakeholders. The process of development was participatory, and was based on existing countryand evidence-based tools and guidelines.

The mechanism, the tools and guidelines were approved by relevant authorities for use in implementation areas, based on specific field needs identified during the process of implementation, and by the local health and family planning authority. At district and sub-district (upazila) level, MNDR review committees were formed to review and analyse the deaths that occurred. Essential training was given to healthcare providers, and as a result they could participate actively in the process. 
MNDR involves the notification of all maternal, neonatal deaths and still births in a district by heath and family-planning staff, including Health Assistants (HAs) and Family-Welfare Assistants (FWAs). The HAs and FWAs were asked to notify deaths in specific areas with the upazila as the MNDR focal point. Providers used a structured death-notification form to collect information from the community and report to the upazila health manager. During monthly and quarterly review meetings, upazila and district MNDR committees discussed the findings of the actual deaths, prepared local remedial action plans, and also made recommendations at a national level to improve maternal and neonatal health services in Bangladesh.

\subsection{Overview of the Study Area}

Thakurgaon District, with a population of 1,450,000 is situated in the northern part of Bangladesh, and has an area of 1809 square kilometres. The district is surrounded by India to the north-west, and is otherwise bordered by two further districts of Bangladesh. Kashipur Union, a small administrative unit in Ranishankoil Upazila, with a population of approximately 28,000 within Thakurgaon District, was selected for this study.

\subsection{Health Facilities Utilizing the MNDR System from Community to District Level}

The smallest unit to provide healthcare at the community level in Bangladesh is the Community Clinic (CC). Each CC provides health services to approximately 6000 - 12,000 people in villages and is responsible for providing primary healthcare. This includes supplying medicines, checking pregnant mothers and the newly born and referring patients onwards. The next level of health care after CCs are union health facilities (rural health centre or union sub center or union health \& family welfare center), covering populations of about 25,000 to 30,000 . The centres are responsible for providing family-planning services, antenatal care, performing normal deliveries, and for referring complicated cases to upazila health complexes (UHCs). The upazila health complexes are the primary-level healthcare referral centres and cover populations of around 200,000 to 300,000. Each hospital has 31 to 50 beds, and manages the health of mothers and children, including the provision of normal deliveries. In some cases, treatment is provided for patients with complications and some centres perform caesarean sections [15] (see Figure 1). The level after the upazilas is the district hospitals, which are the secondary healthcare centres that provide services and care for patients in entire districts. The centres are also responsible for further transferrals of patients to tertiary specialized hospitals.

\subsection{The Government Health and Family-Planning Staff Involved in MNDR at District Level}

HAs and FWAs are staff working at household level in the communities [16]. They are responsible for activities at field level, and are also assigned to the CCs to provide primary care at a local-community level. In the MNDR system, HAs and FWAs are responsible for notifying maternal and neonatal deaths in the community, within three to seven days after a death occurring, to the focal points at the upazila health complexes. Health Inspectors (HIs), Assistant Health Inspectors (AHIs) and Family Planning Inspectors (FPIs) are the first-line supervisors for the HAs and FWAs, and are also responsible for managing the MNDR [16]. At upazila level, MNDR committees are led by upazila health and family-planning officers (UH \& FPOs), who are responsible for supervising and monitoring the MNDR system in each upazila. The UH \& FPOs from the upazilas periodically report on their MNDR systems to district MNDR committees. The district MNDR committees are led by the Civil Surgeon, who is responsible for the district MNDR systems (see Figure 2).

\subsection{Study Design}

Both qualitative and quantitative methods were used to perform the study. Information on numbers of maternal and neonatal death notifications were collected using the structured death-notification form in the MNDR system, while the status of the Kasipur Community Clinic was established from government records.

In-depth interviews (IDIs), a focus-group discussion (FGD) and a group discussion (GD) were used to collect qualitative information. The IDIs, GD and FGD were conducted at the Kashipur Jhaportola Community Clinic in Ranishankoil Uapzila.

The FGD was performed with the Community Clinic Committee, consisting of a chairman, membership secretary, and other members. The number of respondents was seven. The GD was performed with healthcare providers at the CC, including the HA, the FWA and the AHI. The IDIs were conducted with clients who received 


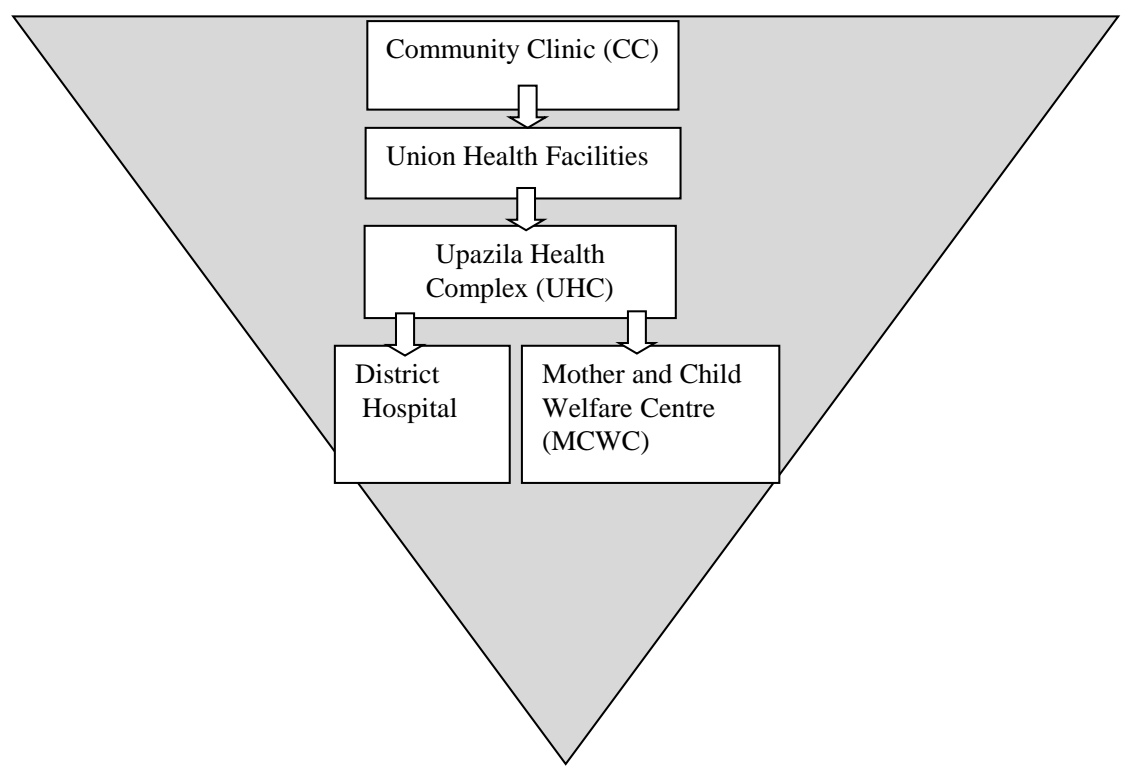

Figure 1. Health facilities utilizing MNDR from community to district level.

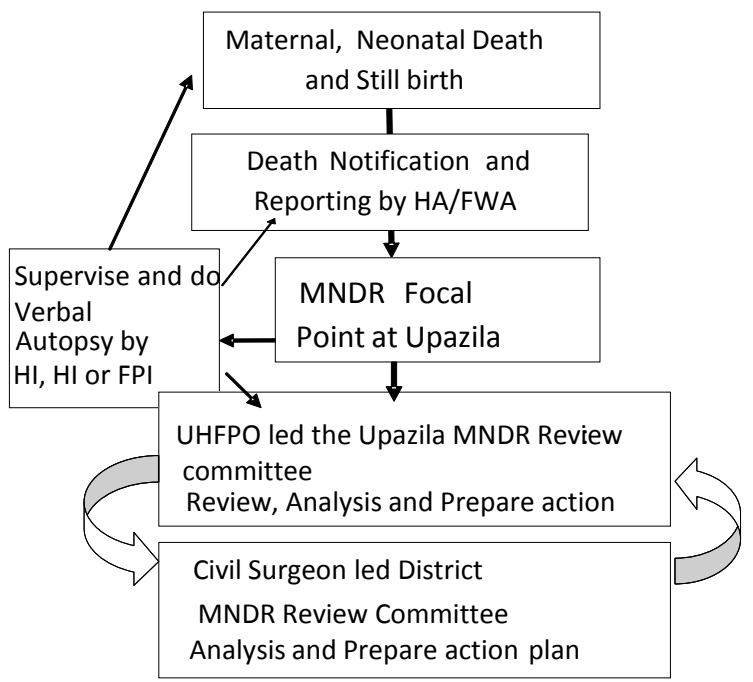

Figure 2. The role of the government's heath and family planning department in MNDR.

antenatal care (ANC) at the CC, the land donor for the CC, and a medical doctor (Bachelor of Medicine and Bachelor of Surgery) who was involved in providing care at the CC (Table 1). Preliminary discussion sessions were held during September 2011.

The interviewer team consisted of a public-health specialist, a minute taker, and a facilitator. After a number of field tests, a series of guidelines and prompts were developed for use during the FGD (Table 2) and the GD (Table 3). During the interviewing, the facilitator followed the guidelines when discussing the community care of mothers at the CC. In this way, the prompts were used to explore the information desired from the FGD and the GD. The interviews were recorded on audio tape, and some of the thematic points were noted in the minutes. After the interviews, the team prepared transcripts by listening to the audio tapes and preparing a first version in Bangla (Bengali). Then, a second version was obtained through translation into English. The transcript of each interview was reviewed on a thematic basis. For each of the themes, findings from the interviews were extracted, and quotations were marked. A qualitative analysis was performed on the basis of the key information obtained and the prompts used during the FGD, the GD, and the IDIs. 
Table 1. Participants in the qualitative study.

\begin{tabular}{cll}
\hline Qualitative instruments & Age range & \multicolumn{1}{c}{ Participants } \\
\hline FGD & $30-45$ years & $\begin{array}{l}\text { Community Clinic Committee, consisting of Chairman, Membership Secretary } \\
\text { (FWA) and nine other members: one school teacher, one religious leader (Imam), } \\
\text { one local leader, and six farmers. }\end{array}$ \\
GD & $35-50$ years & $\begin{array}{l}\text { Health Assistant (HA), Family Welfare Assistant (FWA), Assistant Health Inspector } \\
\text { (AHI). } \\
\text { One pregnant mother who received antenatal care at the CC, one MBBS doctor, and } \\
\text { the donor of land for the CC. }\end{array}$ \\
\hline
\end{tabular}

Table 2. Content of the focus-group discussion.

\begin{tabular}{|c|c|}
\hline Area of discussion & Prompts used \\
\hline Services at the community clinic now & Who is involved? Who comes? Who provides care? What type of care is provided? \\
\hline Services at the community clinic a year ago & Who was involved? Who came? Who provided care? What type of care was provided? \\
\hline Development of the referral system & How is the system developing? How is it functioning? \\
\hline Committee's involvement in the referral system & How are patient referrals carried out? \\
\hline Challenges and successes & What are the challenges/achievements of community care? \\
\hline Community participation & How is the community involved in the seeking of healthcare/the services provided? \\
\hline
\end{tabular}

Table 3. Content of the group discussions.

\begin{tabular}{|c|c|}
\hline Area of discussion & Prompts used \\
\hline Services at the community clinic now & Who is involved? Who comes? Who provides care? What type of care is provided? \\
\hline Services at the community clinic a year ago & Who was involved? Who came? Who provided care? What type of care was provided? \\
\hline Development of the referral system & How is the system developing? How is it functioning? \\
\hline Committee’s involvement in the referral system & How are patient referrals carried out? \\
\hline Challenges and successes & What are the challenges/achievements of community care? \\
\hline
\end{tabular}

\section{Results}

\subsection{Notifications of Maternal and Neonatal Deaths in Kashipur Union though MNDR}

During 2010, the MNDR death-notification system identified Kashipur as a union with a high death density in the Ranishankoil Upazila of Thakurgaon, which itself has a high incidence of maternal and neonatal deaths, and still births. A total of 40 deaths were notified in the union in 2010, of which 4 were maternal deaths, 21 neonatal deaths, and 15 still births (Table 4).

\subsection{Initiatives by Health and Family-Planning Managers and Policy-Makers to Improve Maternal and Neonatal Health Services}

The death-notification findings of Kashipur in 2010 were initially disseminated in the upazila MNDR review meeting. The committee identified four maternal deaths in a village of Kashipur. It was found that the CC in Kashipur did not provide maternal and neonatal health (MNH) services, and there was a discussion over whether the high death toll could be due to the union being situated 30 kilometres away from the Upazila. Moreover the Union is a border union, with very poor socio-economic conditions, a low level of education, and a dense population. The area is agriculture-based, and its mud roads are submerged during the rainy season. People living in the villages also have superstitions about maternal-health issues.

During pregnancy, a mother accepted a number of the beliefs widely held in the community of the Thakurgaon district. Some families felt that if a mother eats more, the baby inside the uterus will be larger, and a normal delivery cannot be performed. The family (mother-in-law/father-in-law) was also resistant to the mother taking vitamins and minerals, because it was felt that vitamins and minerals also make the baby bigger. They also believed that that the primary healthcare centre at the upazila health complex would always have a male 
Table 4. Deaths notified in Kashipur union, Ranishankoil Upazila, Thakurgaon, 2010-2012.

\begin{tabular}{cccc}
\hline Death notifications & 2010 & 2011 & 2012 \\
\hline Maternal deaths & 4 & 1 & 1 \\
Neonatal deaths & 21 & 20 & 8 \\
Still births & 15 & 8 & 13 \\
Total & 40 & 29 & 22 \\
\hline
\end{tabular}

doctor to check on pregnant mothers, and would always try and perform a caesarean section. There was also the myth that the doctors and nurses intentionally changed the position of the baby manually from the outside, which is why normal delivery could not be performed. In this society, it was generally understood that a traditional birth attendant with many years of experience is the right person to perform a delivery. With this view, treatment from a traditional healer can minimise complications during pregnancy. Some of the family felt that there is a chance of an attack from evil forces if a mother goes outside the home during pregnancy. Moreover, during complications, such as a convulsion, people argue that the woman has been invaded by an evil spirit.

Considering the context, the local committee recommended upgrading the CC in Kashipur. A district MNDR committee meeting agreed with the recommendation and participated in a national-level meeting that took the initiative to upgrade the CC. The line director for primary healthcare at the DGHS and other stakeholders found the MNDR system to be an important tool for capturing maternal and neonatal mortality scenarios at the local level, and the meeting determined to renovate and upgrade the CC in Kashipur. A trained community skilled birth attendant (CSBA) was deployed to perform antenatal care, normal delivery, and postnatal care at the facility. All the necessary logistics/equipment, such as a delivery table, weighing machine, blood-pressure monitor, gloves, delivery kit, drugs, etc., were supplied (Figure 3).

\subsection{Changes in the Perceptions of Service Providers and the Residents of Kashipur Union}

During the FGD with the CC committee members and the GD with health providers, it was found that after renovating the CC more people living in Kashipur Union were coming to the CC to seek treatment (which was less frequent in 2010). Moreover, as the following extracts show, healthcare providers working in the area also explored new dimensions to their work:

"Maternal and neonatal healthcare services did not use to be available in the CC; we provided care and advice on family planning, some drugs, and also child vaccinations" (field-level healthcare provider, GD participant).

"People weren't aware that they could seek care or treatment for complications during pregnancy, during delivery, and after delivery that can cause deaths among mothers and the newborn" (GD participant).

"We didn't have any equipment to provide for ANC, and therefore mothers didn't receive ANC from Kasipur CC previously. Some of them sought care from NGOs, private clinics, etc.” (GD participant).

The qualitative data also showed the importance of spreading information about available services:

"It all becomes possible when people start to get the information that the CC is providing for ANC and normal delivery. We talk to the villagers and inform them; field-level health staff go door to door, and tell them about the care available at the CC. People are now starting to move towards the CC” (FGD participant).

"Every three months I sit down with mothers in the villages, talk to them about the healthcare facilities available in the CC, and make some suggestions. So, they are now aware of the services. We also give our mobile number to them, so they can call us in an emergency" (FWA, GD participant).

The participants spoke of the importance of MNDR:

"MNDR has shown the number of deaths in our union; before, we never knew how many mothers and children were dying, or why. It is now our responsibility to save the rest of the women who will get pregnant or are pregnant even now" (GD participant).

"We organized a social autopsy of the deaths that occurred in Kashipur in 2010. It's a component of MNDR which is an awareness meeting in the presence of a family that had experienced a death with neigh- 


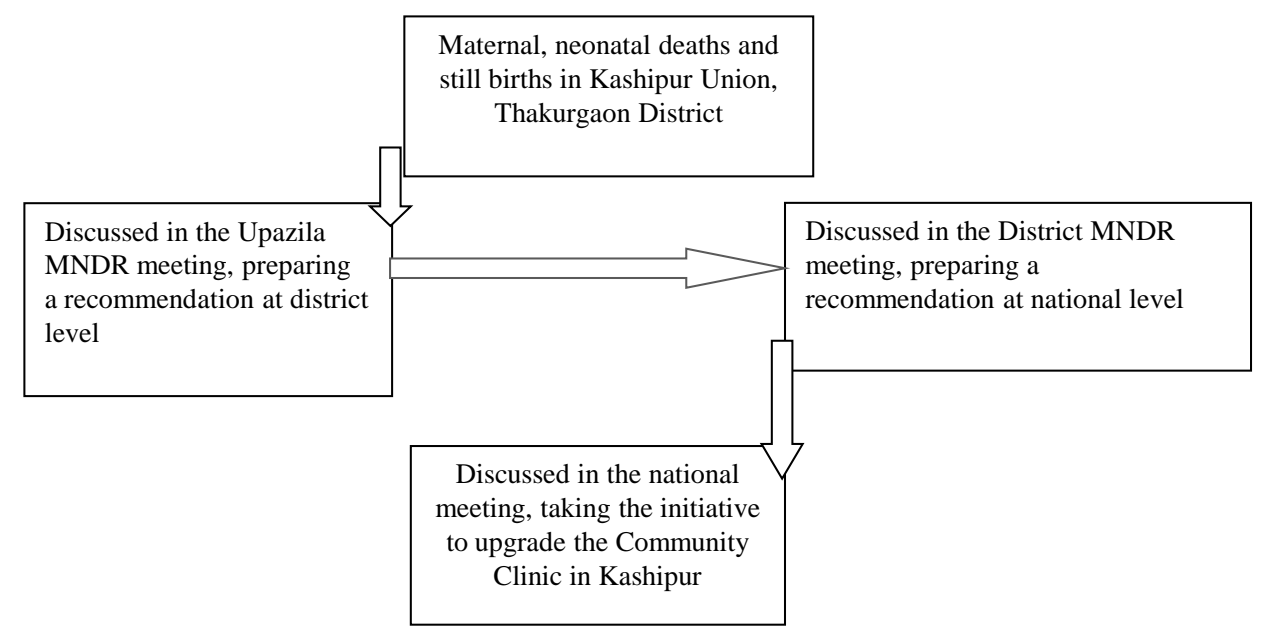

Figure 3. Policy-level decisions to improve facility-based MNH.

bours nearby; and a discussion of that specific death, scrutinizing social failures or other occurrences to determine why it happened, and how it can be prevented from happening in the future through individual or group action. We talked to people and gave the message that they can get better health and a better life. Social autopsy enabled people to realize their errors” (GD participant).

\subsection{Mother's Statements about the Healthcare Facility in Kashipur}

According to the statement of an eight-month pregnant mother, ANC is now easily available in the village, and pregnant mothers living in Kashipur now seek healthcare on a daily basis. The mother said:

"It's my third pregnancy, my first child was born ten years ago, second child aged eight years; in both cases, delivery was at home, baby come out spontaneously when the labour pain started, and one of my relatives cut the umbilical cord. I never received any ANC; I didn't know about it; there was no CC, and we didn't have any opportunity to go to hospital. I didn’t even know about danger signs for the mother, about birth planning. This time, a health worker came to my home, and told me about services at the CC, and asked me to go there. I went to the CC after six months of pregnancy, and now I come every Saturday; it's near my home. One female health worker checks my blood pressure and pulse, measures my weight, examines my abdomen, and gives me medicine and advice. She has also given me a pregnancy card with everything written down. This time, I plan to deliver my child in the CC. I will not take any risks; I have seen many mothers deliver children in this CC in the last few months with the help of the trained female health worker. I am very pleased to get the service and now I am conscious of my health. Last week my weight was $50 \mathrm{~kg}$, this week it’s $49 \mathrm{~kg}$, so I am aware, and will eat more to gain weight, since I get that advice from the CC” (GD participant).

\subsection{Community Involvement}

People living in Kashipur believe that primary health is possible at the village level; the villagers' responsibility is to maximize support for accelerating activities in the CC, and then they start to practice healthcare-seeking. Villagers are also engaged in the renovation of the CC.

During the FGD, one CC committee member said:

"The villages far away from the upazila health complex are very tough to reach in cases of emergency due to the mud roads and the unavailability of vehicles. We notice that pregnant mothers are coming to the CC; we have talked to the upazila authority, and organized a three-wheel non-motorized vehicle from our own donations. One person will drive the vehicle to the village; during an emergency at any time, he will be called on to transport the patient to the UHC; therefore, delays in transporting patients will be minimised" (FGD participant).

Another participant stated: 
"Previously, a number of mothers and babies died on the way to the facility in our village. It took about four to six hours to get there, but now village people are assured that any maternal or neonatal emergency can be referred from the village. People in the community now own the CC, and they want to get maximum service from here. Also, we are happy to provide it” (FGD participant).

The CC committee informed the health department that the CC was to be extended into a ten-bed hospital, which was a request from the community to the government to save mothers and newborn babies. The committee talked to villagers living around the CC about land donation, since the government had only minimal capacity. During the FGD, one committee member said:

"We talked to a land owner, who then donated land to the CC. The CC extended its scope for care. If it turns into a ten-bed hospital, many people will benefit. The land owner agreed to donate a piece of land to extend the building that houses the CC” (FGD participant).

During an in-depth interview, the land donor said:

“I’m old, and I will leave the world at any time. My sons and daughters are married and live separately. I was informed by the CC committee about the CC extension. I'm very happy to know about it. I have seen the health care system during the British and the Pakistan time: Kashipur had nothing; there was no was no way of visiting Kashipur; there were no roads; there were no health facilities; years back, many mothers and children died without any treatment. I lost my wife, I'm alone now; if I get the chance, then local people will get the facility. The lives of mothers and children in the village can be saved. I don't want any more deaths, that's why I donated the land. I'm so pleased about the service in the CC; my younger daughter is now receiving ANC from this CC, so her delivery will be safe” (land donor, IDI).

\subsection{Strengthening of Community Care Services}

Since January 2011, after renovation of the CC in Kashipur, antenatal care, post-natal care and normal deliveries have taken place. The CC is open six days a week from 9am to $2 \mathrm{pm}$. People visit to obtain primary care and MNH services. Some essential drugs, like calcium, vitamins, iron, paracetamol and antibiotics, are supplied to the patients.

During the GD, one participant said:

"We guarantee ANC to pregnant mothers, and perform normal deliveries and also post natal care (PNC). Women now come in just after they get pregnant for advice and a check-up. People in the community have been informed that services in the CC are now available. They've also been told that the health department is now providing sufficient medicine for primary care; we are now able to give our people the drugs they require" (GD participant).

Health providers mentioned that the CC provided ANC to 30 mothers each month, and performed 110 deliveries during 2011/2012. The accessibility of health services was seen as an important benefit:

"The people living in these villages are really satisfied because they don't need to travel far to receive treatment, or seek treatment from a village doctor or quack" (GD participant).

"Now we feel that mothers' lives can be saved. Last year, we had four maternal deaths. The mothers had their babies delivered by untrained birth attendants in the villages, and never went to any treatment facility. Now, we are astonished that only one mother died in Kashipur in 2011, and that every pregnant mother receives treatment" (member of the CC, FGD participant).

\subsection{Special Care Initiated in the Community}

The District Health Authority decided to deploy an MBBS doctor from the Ranishankoil Upazila Health Complex in Kashipur CC to provide treatment and service to mothers. Mothers with complications can receive treatment from the doctor in the CC.

"I'm really glad to get the opportunity to work in the community, where I now serve once in week. I love doing this because these mothers did not go to the facility before, and I never knew what was happening in the villages. It also gives me a unique opportunity to diagnose complicated cases and healthcare provide 
better facilities to the family" (newly deployed doctor, IDI).

"The disadvantaged people demanded that a good doctor should come to the CC once a week so that any complications during pregnancy could be detected and care given” (GD participant).

"We have informed our villagers and the health providers that an MBBS doctor is now coming to serve us. We are really grateful to our health department” (CC committee member, FGD participant).

\subsection{Strengthening of the Referral System}

In primary healthcare it is very important to develop a standard referral system. Within the current heath structure, the country has community clinics at the village level. At the union level there is a union level family welfare centre, then at the upazila level there is upazila health complexes. At the district level, there is district hospital and also a large number of medical college hospitals at the tertiary level including specialized hospital at national level.

At the village level, Kashipur CC provides an example of how a referral system can be established from the village to the proper referral centre.

"I referred four pregnant mothers to Thakurgaon District Hospital immediately after seeing patients at the CC; one of them had high blood pressure with signs of pre-eclampsia; another had an obstructed labour; and another had prolonged labour. I told them not to wait for a minute. These patients were taken in at the right time, and all the babies were born alive; the mothers and children came back to village with happy faces” (health provider, GD participant).

"If we send any mother to the upazila health complex, she is treated by doctors and if required she will be referred to the district hospital. The health complex provides a free ambulance service to transport mothers with complications to the district hospital” (health provider, GD participant).

\subsection{Reduction in Number of Deaths in Kashipur Union}

Changes in maternal and neonatal death-notification status were found after improving health services in Kashipur (Table 4). At the beginning of 2010, the number of maternal deaths was high in Kashipur. However, after services were started in the CC, according to MNDR data for 2011 and 2012, only one maternal death occurred in each year. The CC performed 110 normal deliveries during these two years, of which 46were in 2011 and 64 were in 2012, which has helped to effect a reduction in deaths in Kashipur.

\section{Discussion}

The MNDR system enabled maternal and neonatal deaths to be captured by field staff of the government's health and family planning department of Thakurgaon District in 2010. The system was able to cover an area called Kashipur, which is situated within Thakurgaon District and had high maternal and neonatal mortality. MNDR drew the attention of upazila and district health mangers to the gravity of the situation, of which they were unaware before MNDR initiation. The MNDR committees at upazila level discussed the high mortality incidence, and prepared an action plan, which they provided to the district committee for finalization. The district-level MNDR committee then made a recommendation to the national MNDR committee. This created an avenue for policy-makers to discuss and implement the upgrading of a village-level community clinic to provide antenatal and postnatal care, and to implement normal deliveries. After the community clinic in Kashipur was upgraded the perceptions of villagers have changed. They are now much more aware of maternal and neonatal healthcare services available. People are coming to seek healthcare, and pregnant mothers in particular are coming to receive antenatal care and to have their babies delivered, with specialised services provided by a medical doctor. A large number of normal deliveries have been performed after the initiative was started. The clinic also refers mothers with complications to more appropriate facilities for treatment.

The strength of this study lies in its use of both quantitative and qualitative methods, which makes a good example of mixed research methods [17] [18]. After the qualitative analysis had been conducted, the three sets of qualitative findings (from the FGD, the GD, and the IDIs) were triangulated, supporting the main conclusions of the study. Also, the quality of the MNDR system proved to be highly effective. A weakness of the study, however, is that no comparison was made with a geographic area where there is no MNDR.

A study has recently been conducted in India, where a Maternal and Perinatal Death Inquiry and Response 
(MAPEDIR) initiative was taken uniquely to identify the social, cultural, economic and healthcare factors responsible for maternal deaths, and also to seek to provide systematic ways of changing these factors. As in this case, the MAPEDIR initiative engaged civil administrations, locally elected constitutional bodies, and socialwelfare departments to draw greater attention to the issue of maternal death [12]. Similarly, a maternal and perinatal audit system adopted in Indonesia requires the active engagement of agencies, policy-makers, and community members [19].

Maternal and neonatal death review is a key element in a strategy to improve the quality of maternal healthcare by addressing the causation of deaths, and consider what could have been done to avert each one of them [20] [21]. The MNDR system identifies high-mortality areas to which greater attention should be paid, and also reduces delays in the initiation of treatment by improving the referral system from the community level to professional medical facilities. Delays in seeking care are often due to a lack of awareness of the risk factors and the danger signs of pregnancy and child birth on the part of family members, which often results in casual healthcare-seeking behaviour [13] [22].

Bangladesh is on its way to achieving Millennium Development Goal 5, that of reducing maternal mortality, but the rate of reduction needs to speed up over the next decade [23]. Since a majority of the deaths occur in rural communities of Bangladesh, MNDR at community level has a major place in developing policy guidelines. The situation has been found to be similar in India, where a maternal death review at the community level is vital in making maternal deaths more visible to community members and policy-makers [12]. Many African countries also undertake maternal death reviews at facility level [24]. One African study concluded that facility-based MDR can be combined with community verbal autopsies. [21]. Community-based maternal death reviews provide insights into the causes of, and contributory factors involved in maternal mortality, and uncover weaknesses in healthcare systems from community to facility level [14].

\section{Conclusion}

Finally, the MNDR system in Bangladesh provides a unique opportunity to capture maternal and neonatal deaths, which enables the identification of high death-density areas in rural communities, and compels policy-makers to focus on community healthcare. The national health system came forward to take an initiative to improve healthcare in the rural community of Kashipur. This gave rise to a shift in the perceptions, knowledge and practices of members of the community, and mobilised people into seeking healthcare at the community clinic. Monitoring of periodic death notification status through the MNDR system in the two years following intervention (2011 and 2012) indicated that the number of deaths, and especially of maternal deaths, fell in Kashipur. The introduction of MNDR to a local area in Bangladesh provides a ground-breaking example of reducing maternal and neonatal deaths, which offers the opportunity to intervene in other vulnerable locations with high maternal and neonatal mortality.

\section{Acknowledgements}

The research has implemented by Directorate General of Health Services (DGHS) in collaboration with Directorate General of Family Planning (DGFP), Ministry of Health and Family Welfare (MOHFW) of Government of the People's Republic of Bangladesh under a Joint GoB-UN Maternal Neonatal Health Initiatives. We are thankful to DGHS and DGFP. We are also grateful to the UNICEF, Bangladesh for providing technical support and financial assistance through funding agencies Ukaid, European Union and Canadian CIDA. Finally, we would like to thank Steve Wills of RNLI for assistance with translation.

\section{Competing Interests}

We have no competing interests to declare.

\section{References}

[1] Chowdhury, S., Banu, L.A., Chowdhury, T.A., et al. (2011) Achieving Millennium Development Goals 4 and 5 in Bangladesh. BJOG: An International Journal of Obstetrics \& Gynaecology, 118, 36-46.

[2] National Institute of Population Research and Training (NIPORT), Mitra and Associates, and Macro International (2009) Bangladesh Demographic and Health Survey 2007. NIPORT, Mitra and Associates, and Macro International, 
Dhaka.

[3] National Institute of Population Research and Training (NIPORT), MEASURE Evaluation, UNC-CH, USA, ICDDR, B. (2011) Bangladesh Maternal Mortality and Health Care Survey 2010. National Institute of Population Research and Training (NIPORT), MEASURE Evaluation, UNC-CH, USA, ICDDR, B.

[4] Shah, I.H. and Say, L. (2007) Maternal Mortality and Maternity Care from 1990 to 2005: Uneven but Important Gains. Reprod Health Matters, 15, 17-27. http://dx.doi.org/10.1016/S0968-8080(07)30339-X

[5] Ronsmans, C., Graham, W.J., Lancet Maternal Survival Series Steering Group (2006) Maternal Mortality: Who, When, Where, and Why. Lancet, 368, 1189-1200. http://dx.doi.org/10.1016/S0140-6736(06)69380-X

[6] World Health Organization (2012) Trends in Maternal Mortality 1990 to 2010. Geneva.

[7] (1992) Programme for the Reduction of Maternal Mortality: Options and Proposals. Center for Population and Family Health, School of Public Health, Columbia University, New York.

[8] Campbell, O. and Ronsmans, C. (1995) Verbal Autopsies for Maternal Deaths: Report of a WHO Workshop, London, 10-13 January 1994. World Health Organization, Geneva.

[9] Anker, M., Black, R.E., Coldham, C., et al. (1999) A Standard Verbal Autopsy Method for Investigating Cause of Death in Infants and Children. World Health Organization, Geneva.

[10] Lassi, Z.S., Haider, B.A. and Bhutta, Z.A. (2011) Community-Based Intervention Packages for Reducing Maternal Morbidity and Mortality and Improving Neonatal Outcomes. Final Report.

[11] World Health Organization (2004) Beyond the Numbers: Reviewing Maternal Deaths and Complications to Make Pregnancy Safer. Geneva.

[12] Dikid, T., Gupta, M., Kaur, M., Goel, S., Aggarwal, A.K. and Caravotta, J. (2013) Maternal and Perinatal Death Inquiry and Response Project Implementation Review in India. Journal of Obstetrics and Gynaecology of India, 63, 101-107. http://dx.doi.org/10.1007/s13224-012-0264-3

[13] Jafarey, S.N., Rizvi, T., Koblinsky, M., et al. (2009) Verbal Autopsy of Maternal Deaths in Two Districts of Pakistan: Filling Information Gaps. Journal of Health Population and Nutrition, 27, 170-183. http://dx.doi.org/10.3329/jhpn.v27i2.3329

[14] Hofman, J.J. and Sibande, N.M. (2005) Review of Community Based Maternal Deaths in Mangochi District. Malawi Medical Journal, 17, 81-84.

[15] Management Information System, Directorate General of Health Services (DGHS) (2012) Health Bulletin 2012, Government of the People’s Republic of Bangladesh, Ministry of Health and Family Welfare.

[16] Bangladesh Bureau of Statistics, Statistics Division, Ministry of Planning, Government of the People's Republic of Bangladesh (2012) Bangladesh Population \& Housing Census 2011.

[17] Cresswell, J. and Plano Clark, V. (2007) Designing and Conducting Mixed Methods Research. Sage, Thousand Oaks.

[18] Tashakkori, A. and Teddlie, C. (2010) SAGE Handbook of Mixed Methods in Social \& Behavioral Research. 2nd Edition, Sage, Los Angeles.

[19] Supratikto, G., Wirth, M.E., Achadi, E., et al. (2002) A District-Based Audit of the Causes and Circumstances of Maternal Deaths in South Kalimantan, Indonesia. Bulletin of the World Health Organization, 80, 228-235.

[20] Lewis, G. (2008) Reviewing Maternal Deaths to Make Pregnancy Safer. Best Practice \& Research Clinical Obstetrics \& Gynaecology, 22, 447-463. http://dx.doi.org/10.1016/j.bpobgyn.2007.10.007

[21] Pearson, L., de Bernis, L. and Shoo, R. (2009) Maternal Death Review in Africa. International Journal of Gynecology \& Obstetrics, 106, 89-94. http://dx.doi.org/10.1016/j.ijgo.2009.04.009

[22] Jafarey, S.N. and Korejo, R. (1993) Mothers Brought Dead: An Enquiry into Cases of Delay. Social Science \& Medicine, 36, 371-372. http://dx.doi.org/10.1016/0277-9536(93)90021-U

[23] Koblinsky, M., Anwar, I., Mridha, M.K., et al. (2008) Reducing Maternal Mortality and Improving Maternal Health: Bangladesh and MDG 5. Journal of Health Population and Nutrition, 26, 280-294.

[24] Dumont, A., Gaye, A., de Bernis, L., et al. (2006) Facility-Based Maternal Death Reviews: Effects on Maternal Mortality in a District Hospital of Senegal. Bulletin of the World Health Organization, 84, 218-224.

http://dx.doi.org/10.2471/BLT.05.023903 
Scientific Research Publishing (SCIRP) is one of the largest Open Access journal publishers. It is currently publishing more than 200 open access, online, peer-reviewed journals covering a wide range of academic disciplines. SCIRP serves the worldwide academic communities and contributes to the progress and application of science with its publication.

Other selected journals from SCIRP are listed as below. Submit your manuscript to us via either submit@scirp.org or Online Submission Portal.
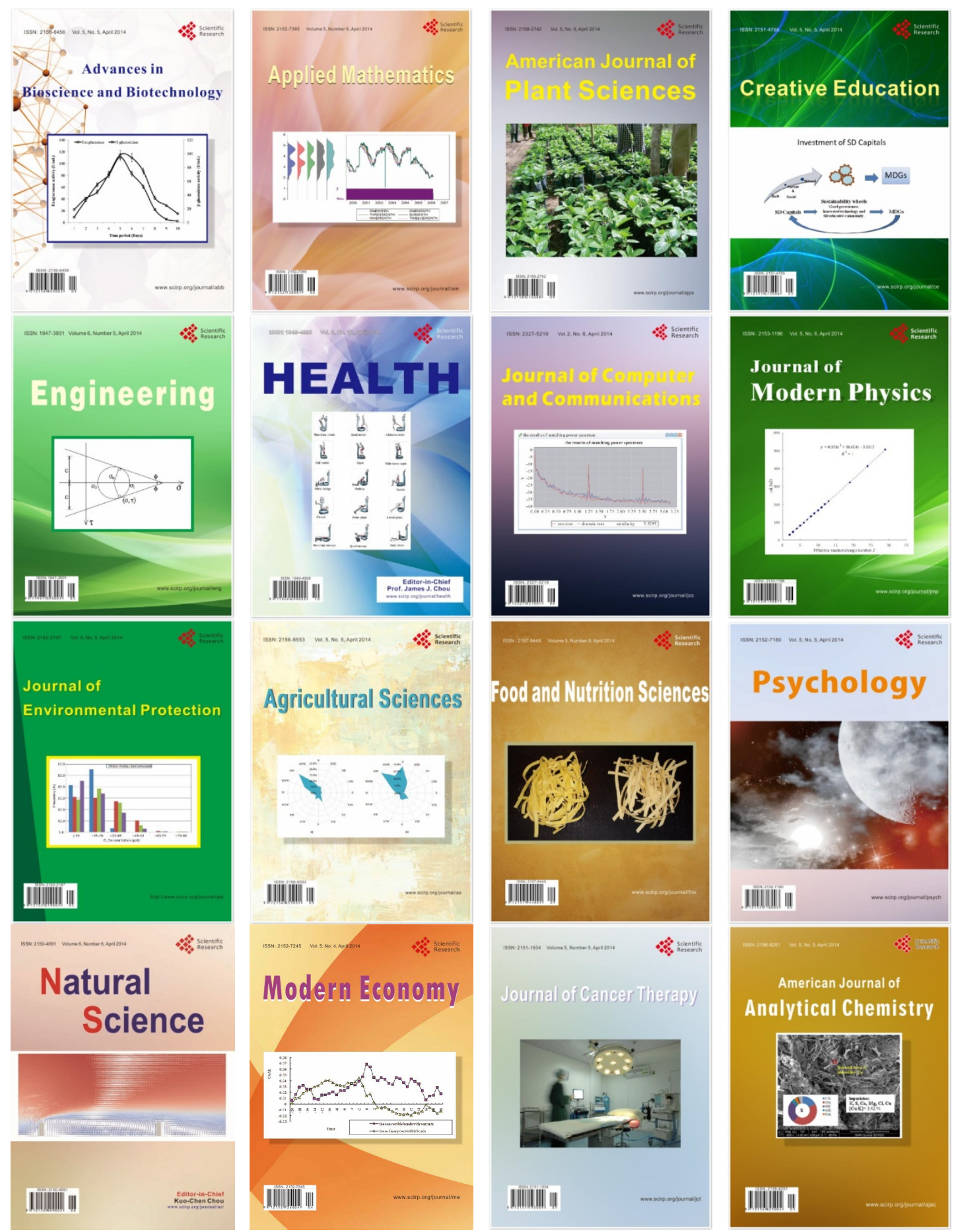